\title{
Characterization of european virgin olive oils using fatty acids
}

\author{
By M. V. Alonso García and R. Aparicio López* \\ Instituto de la Grasa y sus Derivados \\ Avda. Padre García Tejero, 4. 41012-Sevilla, Spain.
}

\section{RESUMEN} grasos.

Caracterización de aceites de oliva virgen europeos usando ácidos

Se ha estudiado la posibilidad de discriminación entre aceites de oliva virgen procedentes de diferentes regiones de España, Italia y Portugal, mediante sus ácidos grasos. Para llevar a cabo la discriminación entre los aceites, desde su agrupación inicial hasta la diferenciación por regiones, se empleó una estructura arborescente. Fueron aplicados procedimientos estadísticos multivariantes para determinar la capacidad discriminante actual de este grupo de compuestos. La certeza asociada a la discriminación final fue calculada mediante la teoría de la evidencia.

PALABRAS -CLAVE: Aceite de oliva virgen (caracterización) - Acido graso - Análisis discriminante - Sistema experto SEXIA - Teoría de la evidencia.

\section{SUMMARY}

Characterization of european virgin olive oils using fatty acids.

The possibility of discriminating between extra virgin olive oils from different regions of Spain, Italy and Portugal, by means of their fatty acid content, has been investigated. A dendrogram allowed discrimination between the oils starting from their initial grouping and progressing to differentiation on the basis of regions. Multivariant statistical analyses were applied to determine the actual discriminatory capacity of this group of compounds. The confidence associated with the final discrimination was ascertained using the theory of evidence.

KEY-WORDS: Discriminant analysis - Fatty acid - SEXIA expert system - Theory of evidence - Virgin olive oil (characterization).

\section{INTRODUCTION}

The methyl esters of fatty acids are considered to be of great use for the chemical characterization of olive oil (Derde et al., 1984; Forina et al., 1983). Insufficiently checked data could artificially increase the discriminatory capacity of this series of compounds. Although, the methodology for their determination is standardized, the simultaneous use of data obtained from different columns or mixtures of oils of diverse qualities - virgin, pure or "lampantes" - is more often responsible for this unusual discriminatory capacity. When the oil is extra-virgin and the quantification methods identical for all samples, the discriminatory capacity diminishes markedly.
In the present work, the value of the fatty acids in discriminating between extra-virgin olive oils from various regions of Spain, Italy and Portugal have been determined (Cad. Oleicola, 1983). A dendrogram permitted differentiation between the oils starting from their initial grouping and progressing to differentiation on the basis of regions. Multivariant statistical analyses have been applied to determine the actual discriminatory capacity of this group of compounds. The confidence associated with the final differentiation was ascertained by means of the evidence theory (Aparicio, R., 1988), as opposed to other methods which use the probability theory (López Sabater et al., 1986) or expert discriminant systems that do not implement possibility theory (Derde et al., 1987).

Numerical and graphic representations demonstrate the discriminatory capacity of the fatty acids, using the probability theory in pairwise comparisons made on the elements of each category. Given the complexity of their numerical representation, graphic representations on maps of Spain, Italy and Portugal have been used to show, by way of example, the results of this possibility theory.

\section{MATERIALS AND METHODS}

\subsection{Chemical methods}

1349 samples of virgin olive oil were analyzed by means of gas chromatography, following norm UNE 55037, 1973.

\subsection{Data analysis and statistical procedures}

The results of tests of skew and kurtosis indicated that the data could be considered normal. No normalization function was applied on the data, as they satisfied the conditions of normality described by Tabachnick and Fidell (Tabachnick et al., 1983; Fisher, G.A., 1936). The usefulness of the F-to-enter test in reducing the possibility of the classificatory equations being due to chance was verified (Lavine et al., 1988).

The rules of decision were constructed on the basis of the discriminant equations obtained by means of the "Stepwise Discriminant Analysis" (SLDA) procedure, inclu- 
ded in the SPSS+X package (2o edition, 1986). The procedure was programmed with the following options:

1. F-to-enter $>4.96$, taking into account a chi-squared distribution at $95.0 \%$.

2. F-to-remove equal to the smallest value calculated by Wilk's Lambda.

3. Mahalanobis' $D^{\star \star 2} 2$ distance.

4. The predictive probability calculated by means of the Jackknife procedure.

\subsection{Presentation and analysis of the results}

The level of significance with which it is possible to affirm that the variances of two distributions are different, are presented in several tables. The following scale, expressed in linguistic terms, has been used:

\begin{tabular}{llcc}
\hline \multicolumn{1}{c}{$\begin{array}{c}\text { Linguistic } \\
\text { Terms }\end{array}$} & $\begin{array}{c}\text { Level of } \\
\text { significance }\end{array}$ & $\begin{array}{c}\text { Sign in the } \\
\text { table }\end{array}$ \\
\hline Completely significant & $\Rightarrow$ & $\quad$ p $<0.001$ & 5 \\
Very significant & $\Rightarrow$ & $0.001<p<0.005$ & 4 \\
Significant & $\Rightarrow$ & $0.005<p<0.01$ & 3 \\
Somewhat significant & $\Rightarrow$ & $0.01<p<0.02$ & 2 \\
Of little significance & $\Rightarrow$ & $0.02<p<0.05$ & 1 \\
\hline
\end{tabular}

The expert system SEXIA has been used to deduce the classificatory final results, using the evidence theory (Aparicio, R., 1988; Aparicio et al., 1981a). An AUTOCAD graphic design package (1991) was used to portray the results on geographical maps of the countries on which the discrimination was performed.

\section{RESULTS AND DISCUSSION}

Figure 1 shows the dendrogram that was designed to determine the discriminant capacity of the fatty acids. Each level shows the groups to be distinguished using this series of compounds. In the first level the differences between the oils from Spain, Italy and Portugal are analyzed. The discrimination was performed by means of pairwise comparisons of the countries e.g. Spain-Italy, Spain-Portugal, etc.

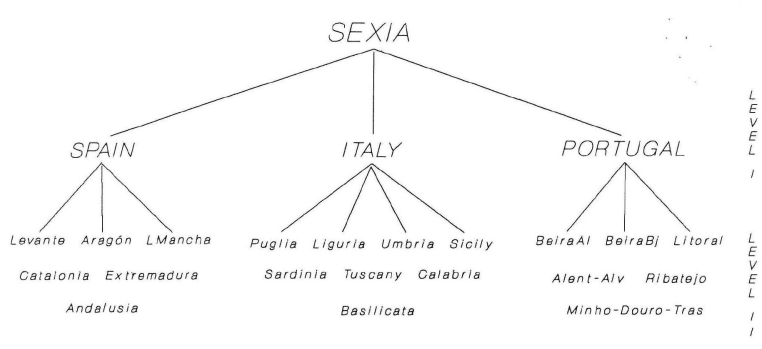

Figure 1

The arborescent structure representing a specific finding taxonomy of SEXIA Expert System.
The following level analyzes the subgroup corresponding to the regions category. At the same time the discriminant capacity of the fatty acids in relation to the categories "provinces" and "zones" was studied. At these levels it was necessary to increase the number of chemical parameters to achieve better discriminatory results.

\subsection{Discriminant analysis between countries}

Figure 2 represents in computerized chromatograms (Aparicio et al., 1981b) the mean values of the seven fatty acids most representative of the oils from the three countries analyzed (table I). As an overall conclusion, it can be noted that there are differences in the fatty acids in the various olive oils, there being a tendency for the mediterranean olive oils to be distinct from the Portuguese oils. The predictive probability levels for countries differentiation are in the cases of Spain-Italy $88.91 \%$, Italy-Portugal $98.77 \%$ and Spain-Portugal $98.52 \%$ of correct classification. It can be seen that, as the latitude of these countries is similar, the predictive levels increase gradually with longitude.

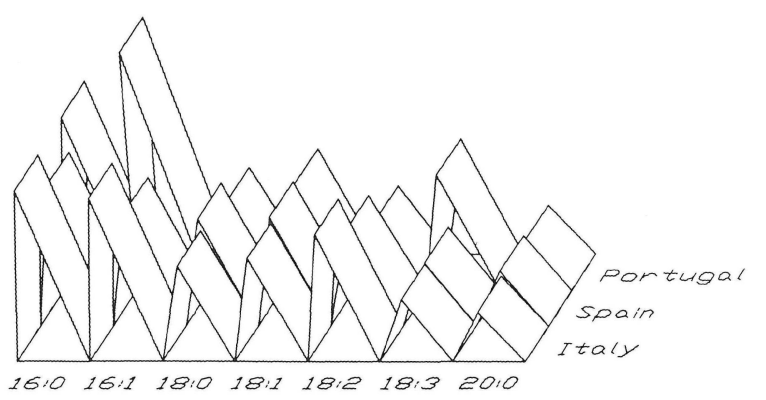

Figure 2

Computerized chromatograms made by the mean values of the most representative fatty acids. Level I. Categories: European countries. Legend: The mean values have been multiplied by the following coefficients: Palmitic $(16: 0)^{\star} 10$, Palmitoleic $(16: 1)^{\star} 100$, Stearic $(18: 0)^{\star} 30$, Oleic $(18: 1)^{\star} 1$, Linoleic $(18: 2)^{\star} 10$, Linolenic $(18: 3)^{\star} 100$, Arachidic $(20: 0)^{\star} 100$.

The computerized chromatograms, together with the probability theory, also allows relational rules to be established, such as:

* IF Stearic ${ }^{\star} 30$ is less than Linoleic ${ }^{\star} 10$

THEN the oil is from Italy

(with a probability of $79.6 \%$ ).

* IF Linoleic ${ }^{\star} 10$ is greater than Linolenic ${ }^{*} 100$

THEN the oil is from Italy

(with a probability of $76.0 \%$ ).

* IF Stearic ${ }^{*} 30$ is less than Linoleic*10 and

Oleic is greater than Linolenic*100

THEN the oil is from Italy

(with a probability of $83.0 \%$ ).

* IF the ratio Linoleic/Stearic is greater than 2.50

THEN the oil is from Italy

(with a probability of $79.0 \%$ )

* IF the ratio Palmitoleic/Stearic is less than 0.25

THEN the oil is from Spain

(with a probability of $61.0 \%$ ) 